\title{
Analysis of alpha-synuclein, dopamine and parkin pathways in neuropathologically confirmed parkinsonian nigra
}

\author{
L. B. Moran ${ }^{1}$, E. Croisier ${ }^{1}$, D. C. Duke ${ }^{1}$, M. E. Kalaitzakis ${ }^{1}$, F. Roncaroli ${ }^{1}$, M. Deprez ${ }^{2}$, D. T. Dexter ${ }^{3}$, R. K. B \\ Pearce $^{1}$, M. B. Graeber ${ }^{1}$ \\ ${ }^{1}$ University Department of Neuropathology, Faculty of Medicine, Division of Neuroscience and Mental Health, Imperial College London and \\ Hammersmith Hospitals Trust, Charing Cross campus, Fulham Palace Road, W6 8RF London, UK \\ ${ }^{2}$ Laboratory of Neuropathology, University Hospital, University of Liège, Liège, Belgium \\ ${ }^{3}$ Department of Cellular and Molecular Biology, Faculty of Medicine, Division of Neuroscience and Mental Health, Imperial College \\ London, London, UK
}

\begin{abstract}
The identification of mutations that cause familial Parkinson's disease (PD) provides a framework for studies into pathways that may be perturbed also in the far more common, non-familial form of the disorder. Following this hypothesis, we have examined the gene regulatory network that links alpha-synuclein and parkin pathways with dopamine metabolism in neuropathologically verified cases of sporadic PD. By means of an in silico approach using a database of eukaryotic molecular interactions and a whole genome transcriptome dataset validated by qRT-PCR and histological methods, we found parkin and functionally associated genes to be upregulated in the lateral substantia nigra $(\mathrm{SN})$. In contrast, alpha-synuclein and ubiquitin carboxyl-terminal hydrolase L1 (UCHL1) gene expression levels were significantly reduced in both the lateral and medial SN in PD. Gene expression for Septin 4, a member of the GTP-binding protein family involved in alpha-synuclein metabolism was elevated in the lateral parkinsonian SN. Additionally, catalase and mitogen-activated protein kinase 8 and poly (ADP-ribose) polymerase family member 1 (PARP1) known to function in DNA repair and cell death induction, all members of the dopamine synthesis pathway, were up-regulated in the lateral SN. In contrast, two additional PD-linked genes, glucocerebrosidase and nuclear receptor subfamily 4, group A, member 2 (NR4A2) showed reduced expression. We show that in sporadic PD, parkin, alpha-synuclein and dopamine pathways are co-deregulated. Alpha-synuclein is a member of all three gene regulatory networks. Our analysis results support the view that alpha-synuclein has a central role in the familial as well as the non-familial form of the disease and provide steps towards a pathway definition of PD.
\end{abstract}

Keywords : Familial Parkinson's disease genes ; Gene regulatory network ; Microarrays ; Pathway analysis ; Systems biology

\section{Introduction}

Parkinson's disease (PD) is the second most common neurodegenerative disorder of adult onset after Alzheimer's disease (AD), and affects between 1 and $2 \%$ of the population over the age of $65[14,20,54]$. The vast majority of clinical PD cases are sporadic. Studies of rare familial forms of PD have so far led to the identification of six genes in which mutations can cause PD [4, 17, 34, 36, 37, 40, 54, 55, 60, 65, 66, 72]. The products of these genes are alpha-synuclein (SNCA), parkin (ubiquitin-conjugating enzyme; UBCH7; PARK2), ubiquitin Cterminal hydrolase L1 (UCHL1), PTEN-induced kinase 1 (PINK), DJ-1 and leucine-rich repeat kinase 2 (LRRK2). Additional loci harbouring presumptive PD genes have been mapped including PARK3 [19], PARK10 [24] and PARK11 [51].

Parkinson's disease results from the progressive death of dopaminergic neurones in the substantia nigra (SN) pars compacta, where neuronal loss is most severe compared to the ventral tegmental area and the central grey [1]. The neuropathological diagnosis of PD was based traditionally on the loss of dopaminergic nigral neurones, accompanying gliosis and the presence of Lewy bodies (LB), eosinophilic intracytoplasmic inclusions, in remaining nerve cells of the SN and neurochemically related nuclei. More recently, an international consensus definition for the diagnosis of PD, which takes into account the SNCA burden of the brain, has been published (http://www.ICDNS.org). According to this definition, assessment of the SNCA status of the PD brain provides 
the key criteria for disease diagnosis. Other investigators have proposed a staging system for the neuropathological progression of PD based on the anatomical distribution of SNCA [5, 13]. However, as this system fails in a significant number of cases and appears to be of limited clinical relevance, we prefer the former consensus reference.

The exact aetiology of common sporadic PD remains elusive, but in addition to age, environmental factors and genetic predisposition are important for its pathogenesis [47, 63]. Biological information on the function of the above PD-associated genes and complementary information obtained from animal studies of the SN further indicate that the selective vulnerability seen in dopamine-producing neurones is functionally linked to an abnormal oxidative stress response [30,74], disturbances in mitochondrial complex I and mitochondrial respiratory-chain enzymes [50,57, 58], as well as ubiquitin-proteasome dysfunction [16, 42]. A functional link indicative of a higher-order pathway connecting the mitochondrial and ubiquitin proteasome subsystems has been described at the transcriptomic level [15].

In the present study, we examined the regulation of genes in which mutations can cause PD (see Supplemental File 1) and of two PD-associated susceptibility genes (glucocerebrosidase, GBA; and nuclear receptor subfamily 4, group A, member 2, NR4A2 or Nurr1). The current study is based on a detailed analysis of a validated microarray data set $[15,45]$, which provides whole genome coverage.

\section{Materials and methods}

\section{Selection of cases}

A total of 15 PD cases and 8 controls were provided by the UK Parkinson's Disease Society Tissue Bank at Imperial College London, the Laboratory of Neuropathology, University of Liège, Belgium, and the UK Multiple Sclerosis Tissue Bank at Imperial College London [45]. Detailed clinical documentation was available for each case. Details of the medication used in the treatment of the PD donors are provided in Supplemental File 2. Clinical histories were assessed by a consultant neurologist (RKBP) and clinical severity ratings were assigned to each case using a semi-quantitative grading score ( 0 , absent; 1 , mild; 2 , moderate; 3 , severe), which takes into account mode and severity of the respective presenting symptom (e.g., motor dysfunction, falls/ataxia, autonomic dysfunction and hallucinations/delusions) (Table 1). No significant trends were observed for age of onset, duration of illness, brain weight, motor dysfunction, falls/ataxia, autonomic dysfunction or hallucinations/delusions (Spearman's correlation). All cases with Parkinsonism had a clinical diagnosis of PD with the exception of one case (case 4) with prominent autonomic dysfunction that had been originally diagnosed as multiple system atrophy (MSA). One further case (case 3) presented with progressive cognitive impairment leading to an additional clinical diagnosis of AD. All non-neurological control cases of this study had no history of neurological or psychiatric disease and showed no signs of confounding pathology upon histological examination as described previously [45]. Correlation analyses were carried out using SPSS (version 13.0).

\section{Neuropathological assessment and diagnosis}

These were performed using international neuropathological consensus criteria for the definitive diagnosis of PD (http://www.ICDNS.org) as mentioned above (Table 1). Alzheimer-type pathology was also assessed (http://www.ICDNS.org). Brain regions routinely sampled included superior frontal gyrus, cingulate gyrus, nucleus accumbens, putamen and caudate, nucleus basalis of Meynert, globus pallidus, hypothalamus with mamillary bodies, amygdala, thalamus, hippocampus, temporal cortex, precentral gyrus, visual cortex, parietal lobe, cerebellum with dentate nucleus, SN, pons at the height of the locus coeruleus, medulla with inferior olive, dorsal motor nucleus of the vagus nerve and the spinal cord at three levels where available. The monoclonal antibodies used to characterise PD and control brains were SNCA (BD Transduction laboratories; dilution 1:300), major histocompatibility complex (MHC) Class II antigens (D-M0775; Dako CR3/43; dilution 1:10), tau (BR-003, Autogen Bioclear UK Ltd; dilution 1:800), ubiquitin (Z0458, Dako; dilution 1:200) and beta-amyloid (VP-B203, Novocastra; dilution 1:25). All immunoreactions for SNCA and MHC class II reactivity were evaluated by two independent observers as described previously [9, 10]. 
Table 1 Clinical and neuropathological characteristics of Parkinson's disease (PD) subjects studied

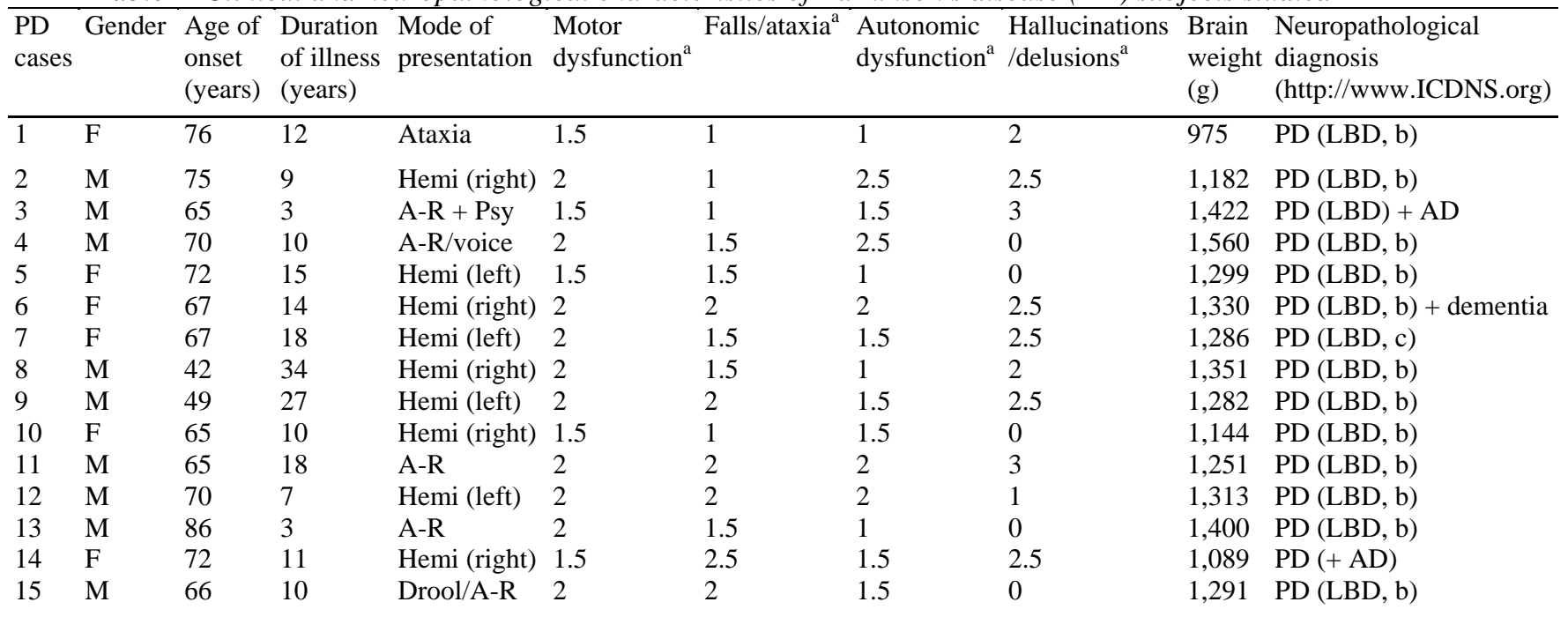

$A D$ Alzheimer's disease, $A-R$ akinetic-rigid, $b$ brainstem predominant, $c$ cortical predominant, drool drooling, $F$ female, $H e m i$ hemiparkinsonism, $L B D$ Lewy body disease, left/right side with predominance of hemiparkinsonism, $M$ male, $P D$ Parkinson's disease, $P s y$ psychiatric symptoms

${ }^{a}$ Semi-quantitative assessment for mode and severity of presenting signs derived from the clinical histories of PD subjects $(0$ absent, 1 mild,

2 moderate, 3 severe)

\section{Microarray work}

Tissue samples dissected from medial and lateral $\mathrm{SN}$ as well as superior frontal gyrus were processed as described [45]. A total of 47 individual tissue samples were analysed, i.e. 15 samples of medial parkinsonian SN, 9 samples of lateral parkinsonian SN, 8 medial nigra control samples and 7 lateral nigra control samples. Lateral and medial nigra samples were from the same cases. Samples of the medial and lateral parts of the SN were taken at the level of the red nucleus. The SN tissue was hand-dissected, trimmed, cut in half and snap frozen. No attempt was made to prepare subnuclei. In addition, the frontal cerebral cortex was analysed in five of the PD cases and in three of the controls. Only cases within a tissue $\mathrm{pH}$ range $>6.0$ and $<6.8$ were used in this study. For each tissue area, total RNA was extracted per case from snap-frozen tissue samples using the RNeasy Mini Kit (Qiagen, Valencia, CA,USA) [44, 45]. Fragmented target cRNA was hybridised to individual arrays (i.e., Affymetrix HG_U133 array set; at total of 94 gene chips were used) [45]. Affymetrix Microarray Suite 5.0 software (MAS5.0) was then used to generate CHP files. CHP and cell intensity (CEL) files of the microarrays were processed using ArrayAssist software (version 3.0; Stratagene Interaction Explorer;

http://www.stratagene.com). The GeneChip Robust Multi Array (GC-RMA) algorithm [68] was then applied. Significance levels (t-test) values for the known PD genes and all pathway components shown in Figs. 1, 2 and 3 are given in Table 2 and Supplemental File 3, respectively (also see [45]). The phrase 'dopamine synthesis pathway' (Fig. 2) is used to describe the dopamine synthesis in a broad sense i.e., not only related to the classical dopamine synthesis pathway starting with tyrosine hydroxylase. Gene expression values were considered statistically different between groups if $P<0.01$ (Student's $t$-test). The commercial Jubilant PathArt database version for PathwayAssist was used for comparative purposes (Moran et al., in press). For the hierarchical clustering, the average linkage method was used with correlation as the similarity metric (ArrayAssist 3.0).

The dataset used in this study will be donated to the public GEO database at http://www.ncbi.nlm. nih.gov/entrez in October 2007 which is the embargo date agreed with the charity that is funding this large programme, the UK Parkinson's Disease Society.

\section{Real-time PCR}

Microarray data were validated using quantitative realtime PCR (qRT-PCR) as described previously [44]. In brief, total RNA from the medial SN of the study cases was initially treated with $2 \mathrm{U}$ of RNase-free DNase (Sigma-Aldrich) and was then reverse transcribed with random decamers using a RetroScript kit (Ambion). Primers to SNCA, UCHL1 and Nurr1 [45] were designed using MacVector 7.0 software (Accelrys, UK) and synthesised by Sigma Genosys, UK. Real-time PCR was conducted using Sybr Green I Mastermix (Applied Biosystems) using an ABI PRISMTM 7700 Sequence Detection System. Raw data was exported to SDS 1.7 
(Applied Biosystems) and analysed as efficiency-corrected normalised expression as described previously [52]. A normalisation factor derived from the geometric mean of the two internal controls (Beclin 1 (coiledcoil,myosin-like BCL2-interacting protein); BECN1 and Glutaminyl-tRNAsynthetase; QARS; [45]) was used to correct for differences in RNA loading. The relative expression (fold differences) in Parkinson's disease versus control medial SN was calculated using Data Analysis for Real-Time PCR (DART-PCR Version 1.0) as described by Peirson et al. [52]. Supplemental File 4 provides additional information on the validation of the expression of selected genes.

Fig. 1 Alpha-synuclein production pathway with summary expression data overlaid (colour coding). Genes upregulated in Parkinson's disease lateral substantia nigra are coloured in red, those that were down-regulated are coloured blue; grey means no change. Small interacting molecules are marked in jade. Differential expression $(D E)$ values represented here are given for the lateral substantia nigra (Table 2). Details of the numerous 26S proteasome subunits are not shown (cf. [15]) because of space limitations. Some genes included in the figure have a less stringent significance level in order to depict the largest possible known gene regulatory network (see Table 2 and Supplemental File 3 for comparison)

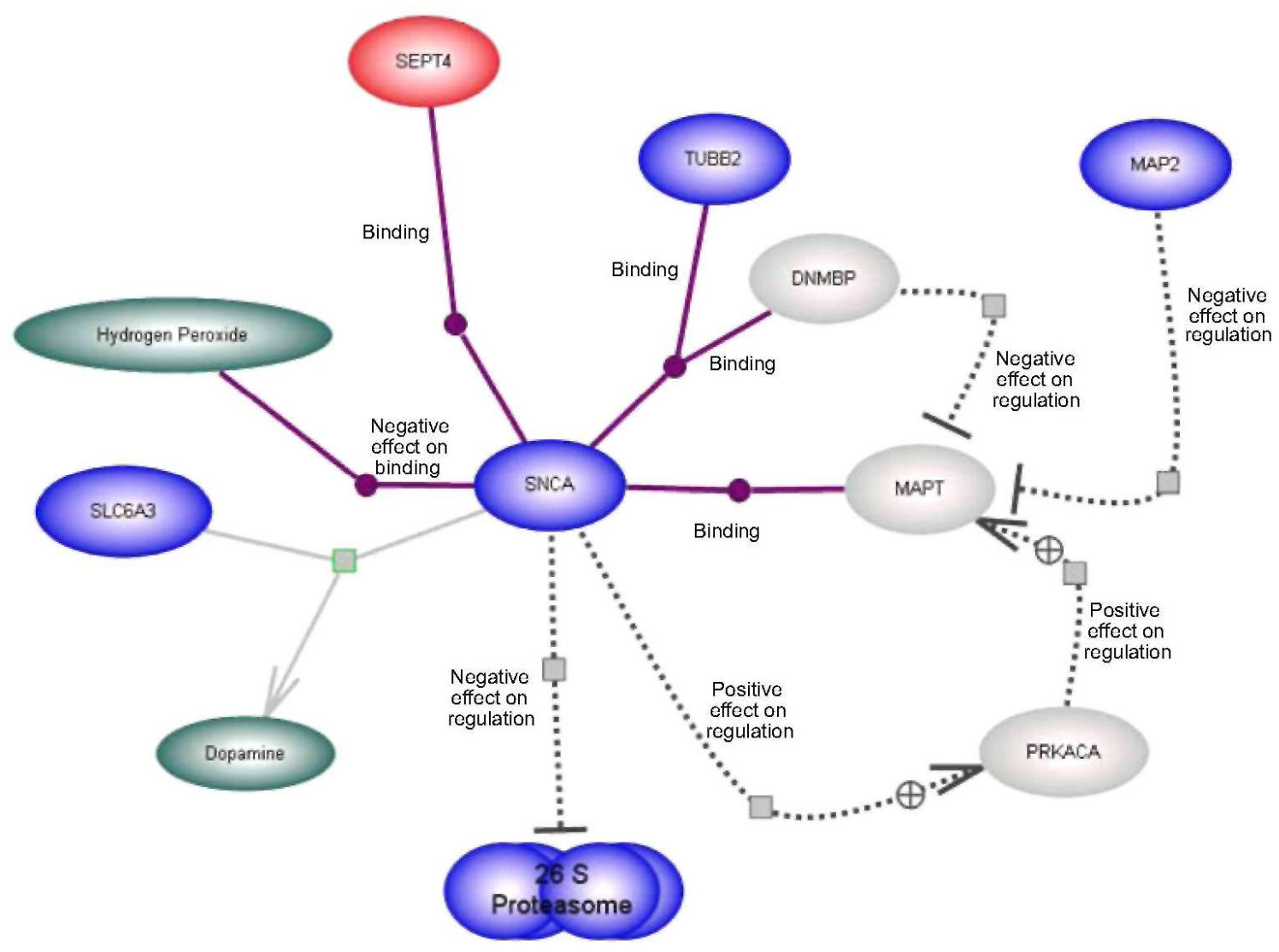


Fig. 2 Representation of the dopamine synthesis pathway. Expression differences between PD and control are given for the lateral substantia nigra (Table 2). Colouring as in Fig. 1. Three genes- poly(ADP-ribose) polymerase family, member 1 (PARP1), catalase (CAT) and mitogen-activated protein kinase 8 (MAPK8)—are significantly up-regulated. Some genes included in the figure have a less stringent significance level in order to depict the largest possible known gene regulatory network (see Supplemental File 3). Transcripts from the NFKB pathway were also significantly up-regulated (Table 2 )

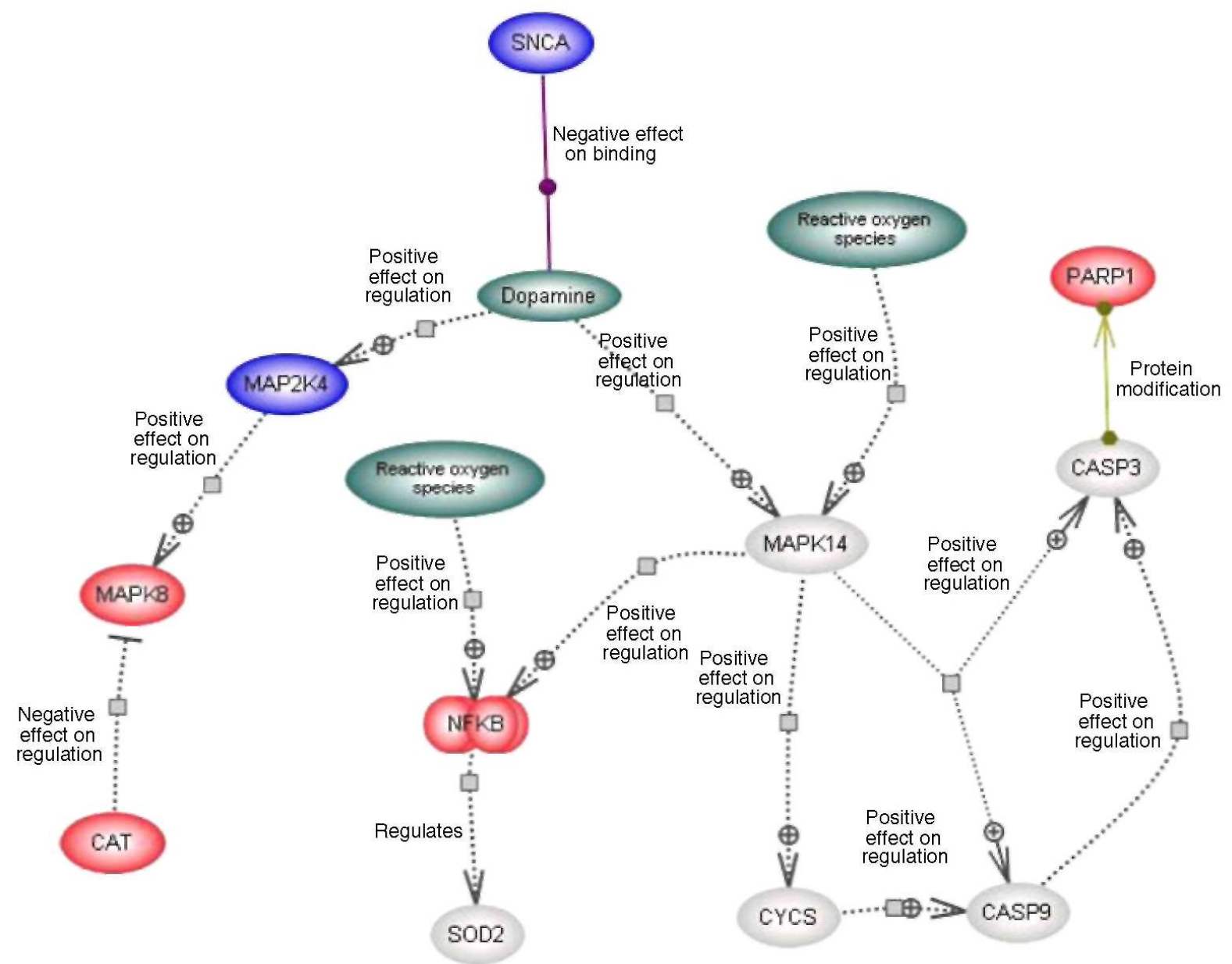

\section{Results}

Expression of the parkin gene was significantly up-regulated in the lateral parkinsonian SN. The expression of SNCA (PARK1) and UCHL1 (PARK5) were significantly down-regulated in both the lateral and medial SN. In contrast, the changes in expression for PINK1 (PARK6), DJ-1 (PARK7) and LRRK2 (PARK8) were not significant at $P=0.061,0.724$ and 0.128 , respectively (Table 2). Several other PD susceptibility-related genes were found to be down-regulated including glucocerebrosidase (GBA) and nuclear receptor subfamily 4, group A, member 2 (Nurr1) (Table 2 and Supplemental File 3). qRT-PCR confirmed the down-regulation in expression of SNCA, UCHL1 and Nurr1 in the medial SN with relative expression differences of $0.26,0.40$ and 0.10 for each gene compared to controls, respectively.

Alpha-synuclein, which is common to all pathways we investigated, interacts with a range of cellular proteins as illustrated by the pathways shown in Figs. 1, 2 and 3 (a reference list for each pathway is provided in Supplemental File 5). The known SNCA production pathway as extracted from the PathArt database is shown in Fig. 1. Apart from sept4, which is significantly increased in the lateral SN, all other pathway components including SNCA are down-regulated in the lateral SN (see Supplemental File 3).

The changes in expression in the dopamine synthesis pathway in the lateral SN in PD brains are illustrated in Fig. 2 (also see Table 2 and Supplemental File 3). Poly(ADP-ribose) polymerase family, member 1 (PARP1) is up-regulated in the lateral SN in our PD cohort. Similarly, mitogen-activated protein kinase 8 (MAPK8), a member of the MAP kinase family also shows increased expression in the lateral SN. Catalase (CAT) is 
significantly up-regulated in both the lateral and the medial SN in our dataset. In addition, we observed that many genes encoding proteins associated with the NFKB pathway are significantly up-regulated in the lateral SN (Supplemental File 3).

Fig. 3 Expression-pathway overlay for parkin metabolism in the lateral substantia nigra in Parkinson's disease. Colour coding as in Fig. 1. Details of the numerous 26S proteasome subunits are not shown (cf. [15]) because of space constraints. Some genes included in the figure have a less stringent significance level in order to depict the largest possible known gene regulatory network (see Supplemental File 3). The association between parkin and t-complex 1 is based on evidence that t-complex 1 plays a role in folding of tubulin, and parkin binds to tubulin

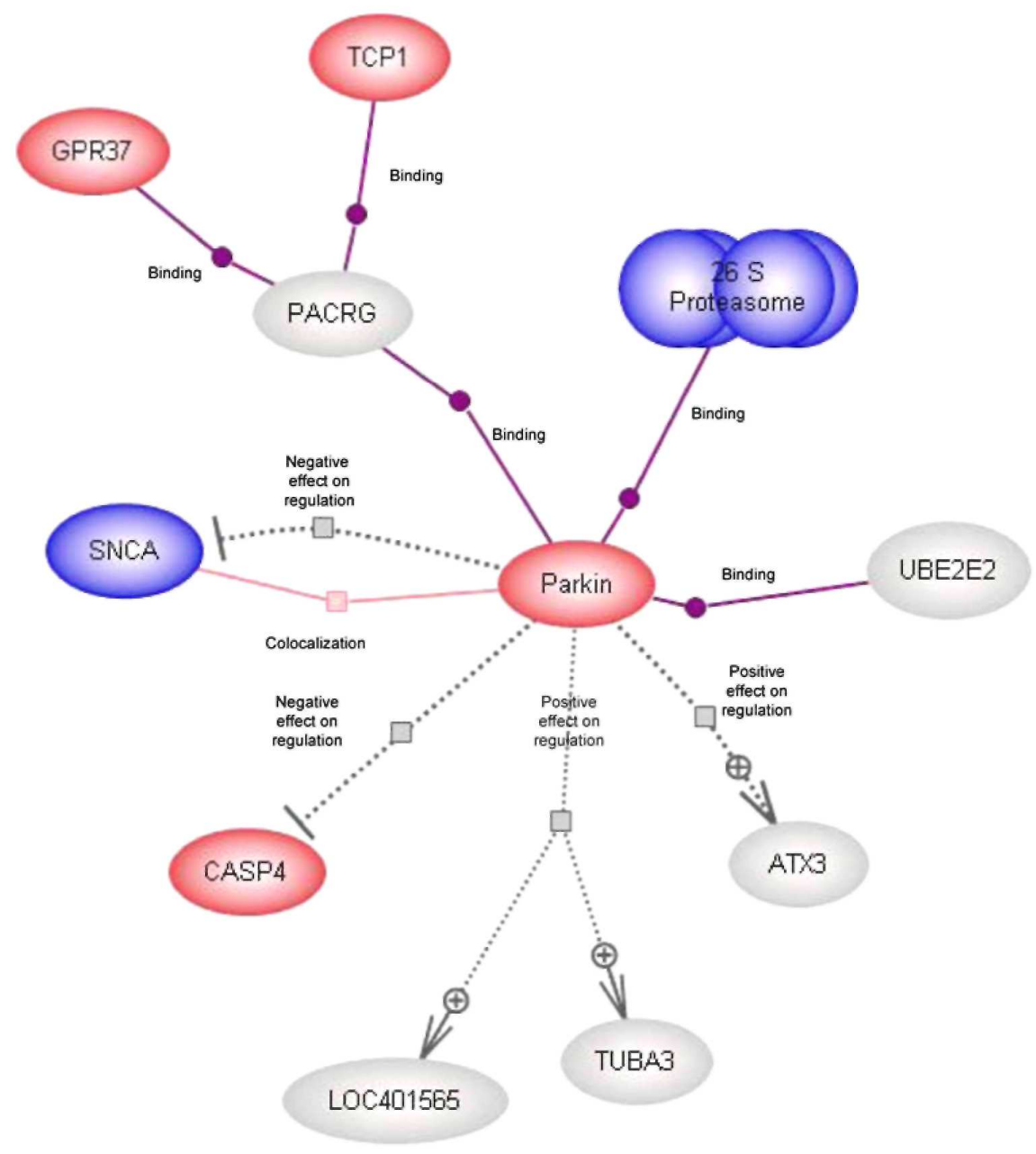

Parkin, an E3-ubiquitin protein-ligase, is a component of the proteasomal pathway. Figure 3 illustrates the other genes that are known to bind and/or influence the regulation of parkin in the SN in PD (Table 2). Parkin is significantly up-regulated in the lateral SN. In our dataset, G-protein-coupled receptor 37 (GPR37), also known as endothelin receptor type B-like or parkin-associated endothelin-like receptor is significantly increased. Tcomplex 1 (TCP1) also has significantly increased expression in the lateral SN. This gene encodes a molecular chaperone that is a member of the chaperonin containing TCP1 complex (CCT) which is suggested to be important in folding newly translated proteins. In addition, caspase 4 (apoptosis-related cysteine protease; CASP4) has significantly increased expression in both the lateral and medial SN in PD.

Hierarchical clustering (Fig. 4) illustrates interesting associations between deregulated genes (cf. Table 2). The top cluster of genes showing highly similar expression includes Nurr1, SCL6A3 [solute carrier family 6 (neurotransmitter transporter, dopamine), member 3], SOD2 (superoxide dismutase 2, mitochondrial), RELA (vrel reticuloendotheliosis viral oncogene homolog A, nuclear factor of kappa light polypeptide gene enhancer in B-cells 3, p65 (avian)), GPR37, CAT, SNCA, UCHL1, MAP2K4 (mitogen-activated protein kinase kinase 4) and TUBB2 (tubulin, beta 2). 
Table 2 Members of gene regulatory networks known to play a role in Parkinson's disease

\begin{tabular}{|c|c|c|c|c|c|c|}
\hline \multirow[t]{2}{*}{$\begin{array}{l}\text { Gene } \\
\text { symbol }\end{array}$} & \multirow[t]{2}{*}{ Gene title } & \multirow[t]{2}{*}{$\begin{array}{l}\text { Probe set } \\
\text { name }\end{array}$} & \multicolumn{2}{|c|}{$\begin{array}{l}\text { Medial substantia } \\
\text { nigra }\end{array}$} & \multicolumn{2}{|c|}{$\begin{array}{l}\text { Lateral substantia } \\
\text { nigra }\end{array}$} \\
\hline & & & $\mathrm{DE}$ & $P$ value & $\mathrm{DE}$ & $P$ value \\
\hline SCL6A3 & $\begin{array}{l}\text { Solute carrier family } 6 \text { (neurotransmitter } \\
\text { transporter, dopamine), member } 3\end{array}$ & 206836_at & -2.206 & 0.000 & -4.044 & 0.000 \\
\hline MAP2 & Microtubule-associated protein 2 & 225540_at & -0.664 & 0.001 & -0.890 & 0.000 \\
\hline SNCA & Alpha-synuclein & 204467_s_at & -1.250 & 0.000 & -1.386 & 0.000 \\
\hline NR4A2 & Nuclear receptor subfamily 4, group A, member 2 & 216248_s_at & -1.509 & 0.000 & -2.404 & 0.000 \\
\hline TUBB2 & Tubulin, beta 2 & 204141_at & -1.167 & 0.000 & -1.350 & 0.000 \\
\hline PARP1 & Poly(ADP-ribose) polymerase family, member 1 & 208644_at & 0.120 & 0.273 & 0.335 & 0.008 \\
\hline UCHL1 & Ubiquitin carboxyl-terminal hydrolase L1 & 201387_s_at & -1.310 & 0.013 & -1.325 & 0.018 \\
\hline CAT & Catalase & 211922_s_at & 0.617 & 0.039 & 0.744 & 0.018 \\
\hline GPR37 & G protein-coupled receptor 37 & 214586_at & 0.492 & 0.084 & 0.898 & 0.018 \\
\hline $\begin{array}{l}\text { MAP2K } \\
4\end{array}$ & Mitogen-activated protein kinase kinase 4 & 203266_s_at & -0.864 & 0.050 & -0.897 & 0.019 \\
\hline MAPK8 & Mitogen-activated protein kinase 8 & 210671_x_at & 0.009 & 0.814 & 0.186 & 0.023 \\
\hline TCP1 & t-complex 1 & 222010_at & 0.288 & 0.077 & 0.482 & 0.031 \\
\hline SEPT4 & Septin 4 & 210657_s_at & 0.412 & 0.090 & 0.573 & 0.034 \\
\hline CASP4 & Caspase 4 , apoptosis-related cysteine protease & 213596_at & 0.153 & 0.027 & 0.162 & 0.035 \\
\hline PARK2 & $\begin{array}{l}\text { Parkinson disease (autosomal recessive, juvenile) 2, } \\
\text { Parkin }\end{array}$ & 207058_s_at & 0.001 & 0.981 & 0.068 & 0.043 \\
\hline PINK1 & PTEN-induced putative kinase 1 & 209019_s_at & -0.233 & 0.210 & -0.394 & 0.061 \\
\hline LRRK2 & Leucine-rich repeat kinase 2 & 229584_at & -0.226 & 0.279 & -0.427 & 0.128 \\
\hline RELA & $\begin{array}{l}\text { v-rel reticuloendotheliosis viral oncogene homolog } \\
\text { A }\end{array}$ & 209878_s_at & 0.139 & 0.444 & 0.206 & 0.272 \\
\hline SOD2 & Superoxide dismutase 2 , mitochondrial & 215223_s_at & 0.153 & 0.655 & 0.356 & 0.568 \\
\hline DJ-1 & - & 200006_at & -0.045 & 0.619 & 0.042 & 0.724 \\
\hline
\end{tabular}

\section{DE differential expression}

Summary table showing expression values and the differences between medial, lateral and control substantia nigra for all established PDcausing genes which were up-regulated in Figs. 1, 2 and 3 and genes derived from hierarchical clustering analysis (Fig. 4). Gene symbols shown are based on Affymetrix probe ontology (abbreviations given in Supplemental File 3). Transcripts showing significant changes in expression are displayed in 'bold' type. Gene expression values of transcripts demonstrating down-regulation are set in 'italics' (see also Supplemental File 3)

In order to depict the largest possible known gene regulatory network, some genes included in the figure have a less stringent significance level 
Fig. 4 Hierarchical clustering for genes important in SNCA production, dopamine synthesis and parkin metabolism (Table 2). Up-regulated genes are depicted in shades of red and yellow, down-regulated genes in shades of blue. Each row represents the colour-coded expression of one gene whereas each column represents one of the study cases. Genes with similar expression patterns are clustering together as shown by the dendrogram (left). Clusters based on similarity between cases are shown in the dendrogram at the bottom. Control cases (case 16, 17, 19 and 23; see [45]) and PD cases (cases 1-7, 11 and 12). There is co-correlation between members of the three pathways-SNCA production, dopamine synthesis and parkin metabolism pathways

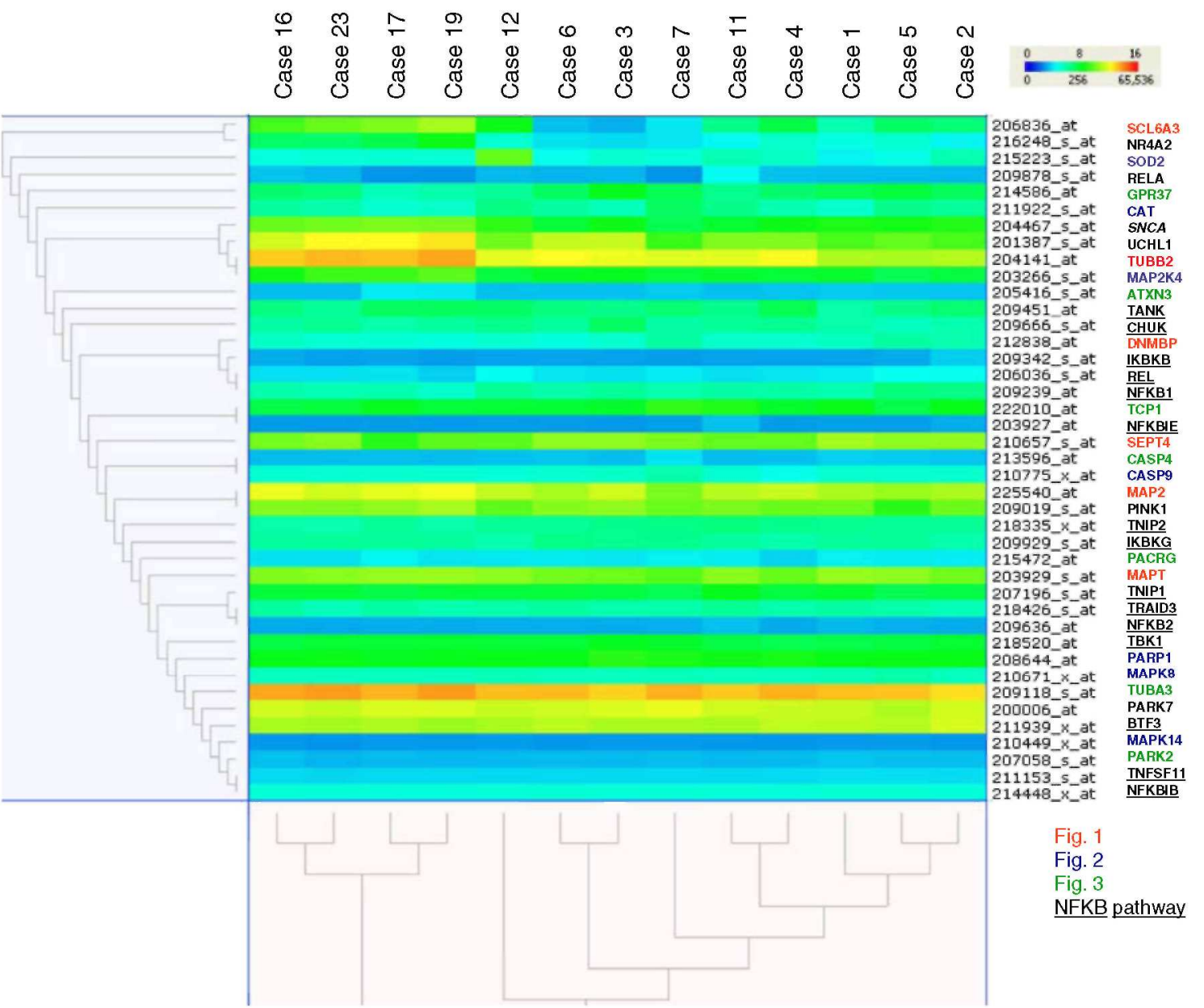

\section{Discussion}

Alpha-synuclein (SNCA) is now considered to play a key role in the pathogenesis of PD and related synucleinopathies (see review [2]). SNCA transcription is significantly reduced (see Table 2) in the parkinsonian SN $[32,48]$. Here, we describe gene regulatory relationships between SNCA and two other pathways considered to be of relevance in PD, dopamine synthesis and parkin metabolism. Supplemental File 6 provides a comparison of our gene list with findings from other microarray studies in SN of sporadic PD (see [22, 23, 43,75]).

In the SNCA production pathway, we report a significant up-regulation of sept4 in the lateral SN. An immunocytochemical study of both PD and other synucleinopathies found sept 4 protein in cytoplasmic inclusions [27]. In AD, sept4, in addition to septl and sept2, accumulates in neurofibrillary tangles [33]. The common role of sept 4 in $\mathrm{AD}$ and $\mathrm{PD}$, both presenting features of abnormal protein processing, suggests the existence of a common pathway linked to neurodegeneration. The increased expression of sept 4 observed in the lateral SN may be associated with the higher attrition of dopaminergic neurones in this anatomical region. Sept4 has been ascribed a role in neuronal differentiation and axon guidance through the control of mitochondrial function [64] and importantly, causes caspase activation [21]. Interestingly, in cultured neuroblastoma and fibroblast cells, co-expression of sept 4 and SNCA synergistically accelerated cell death induced by the proteasome inhibitor, lactacystin [27]. Sept4 [formerly known as bradeion and peanut-like 2 (Drosophila)] is a member of the septin gene family of nucleotide-binding proteins which were originally described in yeast as cell division cycle regulatory factors. 
Parkinson's disease is characterised by a marked reduction in dopamine function, a consequence of massive neuronal loss in the nigrostriatal pathway. In the dopamine synthesis pathway, we find that the enzyme PARP1 is up-regulated. PARP1 negatively modulates SNCA expression by binding to NACP-Rep1, a polymorphic site located upstream of the SNCA gene [7]. PARP1 also functions as a molecular 'nick sensor', binding to DNA single-strand breaks and can silence transcription, preventing the expression of damaged genes (see reviews [12, 73]). Interestingly, excessive activation of PARP1 leads to NAD (+) depletion and cell death in conditions that generate extensive DNA damage [69]. PARP1 also contributes to cell death [35, 53, 70]. A study of ischaemic cell death in neuronal nitric oxide synthase (nNOS) and PARP1 knockout mice illustrated nNOS/PARP-1 signalling is protective in females [41]. CAT, which was up-regulated in the medial and lateral SN, has a known scavenger function for reactive oxygen species generated by metabolic DA oxidation [38]. Furthermore, CAT negatively regulates mitogen-activated protein kinase 8 (MAPK8) [38], a member of the MAP kinase family which also showed increased expression in the lateral SN. MAPK8, also known as JNK/JNK1, is involved in several cellular processes including proliferation, differentiation, transcription regulation and development. In the Drosophila parkin loss-of-function mutants JNK is strongly activated in and may contribute to the vulnerability of the dopaminergic neurones [6].

Four genes were found to be significantly over-expressed in the parkin synthesis pathway, including parkin itself. Parkin is essential for the normal function of the ubiquitin/proteasome pathway. Over-expression of parkin has been shown to protect human dopaminergic neuroblastoma cells against apoptosis induced by dopamine or 6-hydroxydopamine [30]. Parkin also attenuates dopamine-induced activation of JNK and may be important for the survival of dopaminergic neurones exposed to dopamine oxidation [31]. Parkin negatively regulates SNCA [49], and Sp22 - a glycosylated form of SNCA — interacts with parkin [59]. In addition to parkins ability to down-regulate SNCA, synphilin-1 is ubiquitinated by parkin [8], providing further evidence for the interaction between synuclein regulation and parkin metabolism. In the present study, significant changes in parkin expression were only observed in the lateral part of the nigra, which contrasts the result of many genes of the parkin synthesis pathway that show change in both the lateral and medial areas. This may suggest that the latter genes have a potential role in other cellular functions.

In this study we observed a down-regulation of mRNA coding for the 26S proteasome in PD (see Figs. 1, 3). Structural and functional defects in 26/20S proteasomes have been reported in PD (see review [42]), and our observations of a down-regulation support this. Two genes in the parkin pathway were up-regulated, GPR37 and TCP1. GPR37, an orphan G protein-coupled receptor, is a known substrate for parkin [28] and insoluble aggregates of this protein are found in juvenile PD patients [39]. Over-expressed GPR37 protein in dopaminergic neurones becomes unfolded and insoluble, accumulates in the endoplasmic reticulum (ER), inducing ER stress and neurodegeneration [28, 29]. Parkin reduces GPR37 over-expression-induced cell death by ubiquitination in the presence of ubiquitin-conjugating enzymes (resident in the ER) thereby promoting receptor degradation [28]. GPR37 also regulates SN-striatum dopaminergic signalling [39] and has a protective eVect on SN neurones treated with the neurotoxin 1-methyl-4-phenyl-1,2,3,6-tetrahydropyridine [39]. As for TCP1, a member of the chaperonin family, limited information for its role in PD is available. TCP1 has a role in folding of newly translated proteins in the cytosol, including actin and tubulin. Parkin binds to tubulin and increases ubiquitination and degradation [56]. TCP1 is also important in the presentation of misfolded proteins to the proteasome complex and there is evidence of dysregulation of TCP1 in Down syndrome [71]. CASP4, a cysteine protease, also has signiWcantly increased expression in the medial and lateral SN in PD. CASP4 protein can activate its own, as well as caspase 1, precursor proteins. Human caspase-4 is localised to the ER membrane, and is cleaved when cells (human neuroblastoma SK-N-SH and carcinoma HeLa cells) are treated with ER stress-inducing reagents [25], suggesting a role for casp4 as an ER stress-speciWc caspase in humans.

The identification of SNCA mutations in rare familial forms of PD [36, 54, 55] and its abnormal accumulation in LB in nigral [61] and extranigral neurones in sporadic PD has focussed research on the elucidation of the cellular and biological function(s) of SNCA. An ever-increasing body of literature supports the multiple and overlapping roles of SNCA which are visualised in the gene regulatory pathways (Figs. 1, 2, 3). Analysis of co-correlated genes (see Fig. 4) provides clear evidence that SNCA, UCHL1 and parkin are functionally closely connected and linked to the ubiquitin-proteasome pathway. There is considerable evidence for links between DA production and metabolism, AS aggregation and the pathogenesis of PD (see review [18]). Nurr1, one of the highly correlated genes, is known to be important in the differentiation and maintenance of dopaminergic neurones. Mutations in Nurr1 affect transcription of the genes encoding tyrosine hydroxylase and SLC6A3 (see review [26]). SNCA, under normal conditions, negatively modulates dopamine uptake by SLC6A3 [67]. Taken together, our findings strongly support the view that alpha-synuclein has a central role in PD pathobiochemistry. 
Finally, the data presented here were generated from tissue homogenates containing multiple cell types. This seems justified as evidence is accumulating that glial cells can be a primary target of the 'neurodegenerative' disease process (see [11] for review; Slonimsky et al., in preparation). In addition, the widespread pathological alpha-synuclein deposition in PD and the quantity of change observed in our and other studies suggest that PD is a disease of brain tissue rather than of a single cell type. However, there is a scarcity of information on cellular gene expression in the CNS, especially in disease conditions, and much additional work is required to back-map all genes of interest (PD 'priority genes', [45] to individual cellular compartments in the different brain regions of relevance. For this, adoption of a 'universal' oligonucleotide-based hybridisation method [62] may represent an effective way forward [46]. Detailed cellular back-mapping using whole tissue is of great practical importance also because there is a strong focus currently in PD research on only one cell class, the dopaminergic neurone. This is exemplified by a number of laser capture and experimental studies. Should more tissue-based research demonstrate that glia are primarily involved in PD similar to motor neurone disease [3], then this will have significant implications for both diagnostic and treatment considerations including stem cell therapies of PD.

Acknowledgments This work was funded by the UK Parkinson's Disease Society. Tissue samples were supplied by the Parkinson's Disease Society Tissue Bank at Imperial College London, funded by the Parkinson's Disease Society of the United Kingdom, registered charity 948776. We are also grateful to the Multiple Sclerosis Tissue Bank at Imperial College London and the University of Liège for control tissue samples. We express our deepest appreciation to the donors and their families for donating human brain tissue for research.

Electronic supplementary material The online version of this article (doi:10.1007/s00401-006-0181-6) contains supplementary material, which is available to authorized users.

\section{References}

1. Agid Y, Ruberg M, Javoy-Agid F, Hirsch E, Raisman-Vozari R, Vyas S, Faucheux B, Michel P, Kastner A, Blanchard V (1993) Are dopaminergic neurons selectively vulnerable to Parkinson's disease? Adv Neurol 60:148-164

2. Bennett MC (2005) The role of alpha-synuclein in neurodegenerative diseases. Pharmacol Ther 105:311-331

3. Boillee S, Yamanaka K, Lobsiger CS, Copeland NG, Jenkins NA, Kassiotis G, Kollias G, Cleveland DW (2006) Onset and progression in inherited ALS determined by motor neurons and microglia. Science 312:1389-1392

4. Bonifati V, Rizzu P, van Baren MJ, Schaap O, Breedveld GJ, Krieger E, Dekker MC. Squitieri F, Ibanez P, Joosse M, van Dongen JW, Vanacore N, van Swieten JC, Brice A, Meco G, van Duijn CM, Oostra BA, Heutink P (2003) Mutations in the DJ-1gene associated with autosomal recessive early-onset parkinsonism. Science 299:256-259

5. Braak H, Del Tredici K, Rub U, de Vos RA, Jansen Steur EN, Braak E (2003) Staging of brain pathology related to sporadic Parkinson's disease. Neurobiol Aging 24:197-211

6. Cha GH, Kim S, Park J, Lee E, Kim M, Lee SB, Kim JM, Chung J, Cho KS (2005) Parkin negatively regulates JNK pathway in the dopaminergic neurons of Drosophila. Proc Natl Acad Sci USA 102:10345-10350

7. Chiba-Falek O, Kowalak JA, Smulson ME Nussbaum RL (2005) Regulation of alpha-synuclein expression by poly (ADP ribose) polymerase-1 (PARP-1) binding to the NACP-Rep1 polymorphic site upstream of the SNCA gene. Am J Hum Genet 76:478-492

8. Chung KK, Zhang Y, Lim KL, Tanaka Y, Huang H, Gao J, Ross CA, Dawson VL, Dawson TM (2001) Parkin ubiquitinates the alphasynuclein-interacting protein, synphilin-1: implications for Lewy-body formation in Parkinson disease. Nat Med 7:1144-1150

9. Croisier E, Moran LB, Dexter DT, Pearce RK, Graeber MB (2005) Microglial inflammation in the parkinsonian substantia nigra: relationship to alpha-synuclein deposition. J Neuroinflamm 2:14

10. Croisier E, Elfant D, Deprez M, Goldring K, Dexter DT, Pearce RKB, Graeber MB, Roncaroli F (2006) Comparative study of commercially available anti-alpha-synuclein antibodies. Neuropathol Appl Neurobiol 32:1365-2990

11. Croisier E, Graeber MB (2006) Glial degeneration and reactive gliosis in alpha-synucleinopathies: the emerging concept of primary gliodegeneration. Acta Neuropathol (Berl) 112:517-530

12. D'Amours D, Desnoyers S, D'Silva I, Poirier GG (1999) Poly(ADP-ribosylation reactions in the regulation of nuclear functions Biochem J 342:249-268

13. Del Tredici K, Rub U, De Vos RA, Bohl JR, Braak H (2002) Where does parkinson disease pathology begin in the brain? J Neuropathol Exp Neurol 61:413-426 
14. de Rijk MC, Tzourio C, Breteler MM, Dartigues JF, Amaducci, Lopez-Pousa S, Manubens-Bertran JM, Alperovitch A, Rocca WA (1997) Prevalence of parkinsonism and Parkinson's disease in Europe: the EUROPARKINSON Collaborative Study. European Community Concerted Action on the Epidemiology of Parkinson's disease. J Neurol Neurosurg Psychiatr 62:10-15

15. Duke DC, Moran LB, Kalaitzakis ME, Deprez M, Dexter DT, Pearce RK, Graeber MB (2006) Transcriptome analysis reveals link between proteasomal and mitochondrial pathways in Parkinson's disease. Neurogenetics 7:139-148

16. Feany MB, Pallanck LJ (2003) Parkin: a multipurpose neuroprotective agent? Neuron 38:13-16

17. Funayama M, Hasegawa K, Kowa H, Saito M, Tsuji S, Obata F (2002) A new locus for Parkinson's disease (PARK8) maps to chromosome 12pll.2-q13.1. Ann Neurol 51:296-301

18. Galvin JE (2006) Interaction of alpha-synuclein and dopamine metabolites in the pathogenesis of Parkinson's disease: a case for the selective vulnerability of the substantia nigra. Acta Neuropathol (Berl) 112:115-126

19. Gasser T, Muller-Myhsok B, Wszolek ZK, Oehlmann R, Calne DB, Bonifati V, Bereznai B, Fabrizio E, Vieregge P, Horstmann RD (1998) A susceptibility locus for Parkinson's disease maps to chromosome 2pl3. Nat Genet 18:262-265

20. Giasson BI, Lee VM (2003) Are ubiquitination pathways central to Parkinson's disease? Cell 114:1-8

21. Gottfried Y, Rotem A, Lotan R, Steller H, Larisch S (2004) The mitochondrial ARTS protein promotes apoptosis through targeting XIAP. EMBO J 23:1627-1635

22. Grunblatt E, Mandel S, Jacob-Hirsch J, Zeligson S, Amariglo N, Rechavi G, Li J, Ravid R, Roggendorf W, Riederer P, Youdim MB (2004) Gene expression profiling of parkinsonian substantia nigra pars compacta; alterations in ubiquitin-proteasome, heat shock protein, iron and oxidative stress regulated proteins, cell adhesion/cellular matrix and vesicle trafficking genes. J Neural Transm 111:1543-1573

23. Hauser MA, Li YJ, Xu H, Noureddine MA, Shao YS, Gullans SR, Scherzer CR, Jensen RV, McLaurin AC, Gibson JR, Scott BL, Jewett RM, Stenger JE, Schmechel DE, Hulette CM, Vance JM (2005) Expression profiling of substantia nigra in Parkinson disease, progressive supranuclear palsy, and frontotemporal dementia with parkinsonism. Arch Neurol 62:917-921

24. Flicks AA, Petursson H, Jonsson T, Stefansson H, Johannsdottir HS, Sainz J, Frigge ML, Kong A, Gulcher JR, Stefansson K, Sveinbjornsdottir S (2002) A susceptibility gene for late-onset idiopathic Parkinson's disease. Ann Neurol 52:549-555

25. Hitomi J, Katayama T, Eguchi Y, Kudo T, Taniguchi M, Koyama Y, Manabe T, Yamagishi S, Bando Y, Imaizumi K, Tsujimoto Y, Tohyama M (2004) Involvement of caspase-4 in endoplasmic reticulum stress-induced apoptosis and Abeta-induced cell death. J Cell Biol $165: 347-356$

26. Huang Y, Cheung L, Rowe D, Halliday G (2004) Genetic contributions to Parkinson's disease. Brain Res Brain Res Rev 46:44-70

27. Ihara M, Tomimoto H, Kitayama H, Morioka Y, Akiguchi I, Shibasaki H, Noda M, Kinoshita M (2003) Association of the cytoskeletal GTP-binding protein Sept4/H5 with cytoplasmic inclusions found in Parkinson's disease and other synucleinopathies. J Biol Chem 278:24095-24102

28. Imai Y, Soda M, Inoue H, Hattori N, Mizuno Y, Takahashi R (2001) An unfolded putative transmembrane polypeptide, which can lead to endoplasmic reticulum stress, is a substrate of Parkin. Cell 105:891-902

29. Imai Y, Soda M, Hatakeyama S, Akagi T, Hashikawa T, Nakayama KI, Takahashi R (2002) CHIP is associated with Parkin, a gene responsible for familial Parkinson's disease, and enhances its ubiquitin ligase activity. Mol Cell 10:55-67

30. Jenner P, Olanow CW (1998) Understanding cell death in Parkinson's disease. Ann Neurol 44:S72-S84

31. Jiang H, Ren Y, Zhao J, Feng J (2004) Parkin protects human dopaminergic neuroblastoma cells against dopamine-induced apoptosis Hum Mol Genet 13:1745-1754

32. Kingsbury AE, Daniel SE, Sangha H, Eisen S, Lees AJ, Foster OJ (2004) Alteration in alpha-synuclein mRNA expression in Parkinson's disease. Mov Disord 19:162-170

33. Kinoshita A, Kinoshita M, Akiyama H, Tomimoto H, Akiguchi I, Kumar S, Noda M, Kimura J (1988) Identification of septins in neurofibrillary tangles in Alzheimer's disease. Am J Pathol 153:1551-1560

34. Kitada T, Asakawa S, Hattori N, Matsumine H, Yamamura Y, Minoshima S, Yokochi M, Mizuno Y, Shimizu N (1998) Mutations in the parkin gene cause autosomal recessive juvenile parkinsonism. Nature 392:605-608

35. Koh DW, Dawson TM, Dawson VL (2005) Mediation of cell death by poly(ADP-ribose) polymerase-1. Pharmacol Res 52:5-14

36. Kruger R, Kuhn W, Muller T, Woitalla D. Graeber M, Kosel S, Przuntek H, Epplen JT, Schols L, Riess O (1998) Ala30Pro mutation in the gene encoding alpha-synuclein in Parkinson's disease. Nat Genet 18:106-108 
37. Leroy E, Boyer R, Polymeropoulos MH (1998) Intron-exon structure of ubiquitin c-terminal hydrolase-L1. DNA Res 5:397-400

38. Luo Y, Umegaki H, Wang X, Abe R, Roth GS (1998) Dopamine induces apoptosis through an oxidation-involved SAPK/JNK activation pathway. J Biol Chem 273:3756-3764

39. Marazziti D, Golini E, Mandillo S, Magrelli A, Witke W, Matteoni R, Tocchini-Valentini GP (2004) Altered dopamine signalling and MPTP resistance in mice lacking the Parkinson's disease-associated GPR37/parkin-associated endothelin-like receptor. Proc Natl Acad Sci USA 101:10189-10194

40. Matsumine H, Saito M, Shimoda-Matsubayashi S, Tanaka H, Ishikawa A, Nakagawa-Hattori Y, Yokochi M, Kobayashi T, Igarashi S Takano H, Sanpei K, Koike R, Mori H, Kondo T, Mizutani Y, Schaffer AA, Yamamura Y, Nakamur S, Kuzuhara S, Tsuji S, Mizuno Y (1997) Localization of a gene for an autosomal recessive form of juvenile Parkinsonism to chromosome 6q25.2-27. Am J Hum Genet 60:588-596

41. McCullough LD, Zeng Z, Blizzard KK, Debchoudhury I, Hum PD (2005) Ischemic nitric oxide and poly (ADP-ribose) polymerase-1 in cerebral ischemia: male toxicity, female protection. J Cereb Blood Flow Metab 25:502-512

42. McNaught KS, Olanow CW (2003) Proteolytic stress: a unifying concept for the etiopathogenesis of Parkinson's disease. Ann Neurol 53:S73-S84

43. Miller RM, Kiser GL, Kaysser-Kranich TM, Lockner RJ, Palaniappan C, Federoff HJ (2006) Robust dysregulation of gene expression in substantia nigra and striatum in Parkinson's disease. Neurobiol Dis 21:305-313. Epub 6 September 2005

44. Moran LB, Duke DC, Turkheimer FE, Banati RB, Graeber MB (2004) Towards a transcriptome definition of microglial cells. Neurogenetics 5:95-108

45. Moran LB, Duke DC, Deprez M, Dexter DT, Pearce RKB, Graeber MB (2006a) Whole genome expression profiling of the medial and lateral substantia nigra in Parkinson's disease. Neurogenetics 7:1-11

46. Moran LB, Hickey L, Duke DC, Derkacs M, Michael GJ, Croisier E, Dexter DT, Pearce RKB, Graeber MB (2006b) Expression profiling demonstrates cerebral cortex involvement in Parkinson's disease. In: 36th Annual Meeting of the Society for Neuroscience, Atlanta, GA, 14-18 October 2006. Society for Neuroscience Abstracts: 173.2/FF26

47. Mouradian MM (2002) Recent advances in the genetics and pathogenesis of Parkinson disease. Neurology 58:179-185

48. Neystat M, Lynch T, Przedborski S, Kholodilov N, Rzhetskaya M, Burke RE (1999) Alpha-synuclein expression in substantia nigra and cortex in Parkinson's disease. Mov Disord 14:417-422

49. Oluwatosin-Chigbu Y, Robbins A, Scott CW, Arriza JL, Reid JD, Zysk JR (2003) Parkin suppresses wild-type alpha-synuclein-induced toxicity in SHSY-5Y cells. Biochem Biophys Res Commun 309:679-884

50. Orth M, Schapira AH (2002) Mitochondrial involvement in Parkinson's disease. Neurochem Int 40:533-541

51. Pankratz N, Nichols WC, Uniacke SK, Halter C, Rudolph A, Shults C, Conneally PM, Foroud T, The Parkinson Study Group (2003) Significant linkage of Parkinson disease to chromosome 2q36-37. Am J Hum Genet 72:1053-1057

52. Peirson SN, Butler JN, Foster RG (2003) Experimental validation of novel and conventional approaches to quantitative real-time PCR data analysis. Nucleic Acids Res 31:e73

53. Pieper AA, Verma A, Zhang J, Snyder SH (1999) Poly (ADP-ribose) polymerase, nitric oxide and cell death. Trends Pharmacol Sci 20:171-181

54. Polymeropoulos MH, Higgins JJ, Golbe LI, Johnson WG, Ide SE, Di Iorio G, Sanges G, Stenroos ES, Pho LT, Schaffer AA, Lazzarini AM, Nussbaum RL, Duvoisin RC (1996) Mapping of a gene for Parkinson's disease to chromosome 4q21-q23. Science 274:1197-1199

55. Polymeropoulos MH, Lavedan C, Leroy E, Ide SE, Dehejia A, Dutra A, Pike B, Root H, Rubenstein J, Boyer R, Stenroos E.S, Chandrasekharappa S, Athanassiadou A, Papapetropoulos T, Johnson W.G, Lazzarini AM, Duvoisin RC, Di Iorio G, Golbe LI, Nussbaum RL (1997) Mutation in the alpha-synuclein gene identified in families with Parkinson's disease. Science 276:2045-2047

56. Ren Y, Zhao J, Feng J (2003) Parkin binds to alpha/beta tubulin and increases their ubiquitination and degradation. J Neurosci 23:33163324

57. Schapira AH (1998) Human complex I defects in neurodegenerative diseases. Biochim Biophys Acta 1364:261-270

58. Sherer T.B, Betarbet R, Greenamyre JT (2002) Environment, mitochondria, and Parkinson's disease. Neuroscientist 8:192-197

59. Shimura H, Schlossmacher MG, Hattori N, Frosch MP, Trockenbacher A, Schneider R. Mizuno Y, Kosik KS, Selkoe DJ (2001) Ubiquitination of a new form of alpha-synuclein by parkin from human brain: implications for Parkinson's disease. Science 293:263-269 
60. Singleton AB, Farrer M, Johnson J, Singleton A, Hague S, Kachergus J, Hulihan M, Peuralinna T, Dutra A, Nussbaum R, Lincoln S, Crawley A, Hanson M, Maraganore D, Adler C, Cookson MR, Muenter M, Baptista M, Miller D, Blancato J, Hardy J, Gwinn-Hardy K (2003) $\alpha$-synuclein locus triplication causes Parkinson's disease. Science 302:841

61. Spillantini MG, Crowther RA, Jakes R, Hasegawa M, Goedert M (1998) alpha-Synuclein in filamentous inclusions of Lewy bodies from Parkinson's disease and dementia with Lewy bodies. Proc Natl Acad Sci USA 95:6469-6473

62. Storr HL, Clark AJ, Priestley JV, Michael GJ (2005) Identification of the sites of expression of triple A syndrome mRNA in the rat using in situ hybridisation. Neuroscience 131:113- 123

63. Sveinbjornsdottir S, Hicks AA, Jonsson T, Petursson H, Gugmundsson G, Frigge ML, Kong A, Gulcher JR, Stefansson K (2000) Familial aggregation of Parkinson's disease in Iceland. N Engl J Med 343:1765-1770

64. Takahashi S, Inatome R, Yamamura H, Yanagi S (2003) Isolation and expression of a novel mitochondrial septin that interacts with RMP/CRAM in the developing neurones. Genes Cells 8:81-93

65. Valente EM, Abou-Sleiman PM, Caputo V, Muqit MM, Harvey K, Gispert S, Ali Z, Del Turco D, Bentivoglio AR, Healy DG, Albanese A, Nussbaum R, Gonzalez-Maldonado R, Deller T, Salvi S, Cortelli P, Gilks WP, Latchman DS, Harvey RJ, Dallapiccola B, Auburger G, Wood NW (2004) Hereditary early-onset Parkinson's disease caused by mutations in PINK1. Science 304:1158-1160

66. van Duijn CM, Dekker MC, Bonifati V, Galjaard RJ, Houwing-Duistermaat JJ, Snijders PJ, Testers L, Breedveld GJ, Horstink M, Sandkuijl LA, van Swieten JC, Oostra BA, Heutink P (2001) Park7, a novel locus for autosomal recessive early-onset parkinsonism, on chromosome lp36. Am J Hum Genet 69:629-634

67. Wersinger C, Sidhu A (2003) Attenuation of dopamine transporter activity by alpha-synuclein. Neurosci Lett 340:189-192

68. Wu Z, Irizarry RA (2004) Preprocessing of oligonucleotide array data. Nat Biotechnol 22:656-658

69. Ying W, Sevigny MB, Chen Y, Swanson RA (2001) Poly(ADP-ribose) glycohydrolase mediates oxidative and excitotoxic neuronal death. Proc Natl Acad Sci USA 98:12227-12232

70. Ying W, Chen Y, Alano CC, Swanson RA (2002) Tricarboxylic acid cycle substrates prevent PARP-mediated death of neurons and astrocytes. J Cereb Blood Flow Metab 22:774-779

71. Yoo BC, Fountoulakis M, Dierssen M, Lubec G (2001) Expression patterns of chaperone proteins in cerebral cortex of the fetus with Down syndrome: dysregulation of T-complex protein 1. J Neural Transm Suppl 61:321-334

72. Zarranz JJ, Alegre J, Gomez-Esteban JC, Lezcano E, Ros R, Ampuero I, Vidal L, Hoenicka J, Rodriguez O, Atares B, Llorens V, Gomez TE, del Ser T, Munoz DG, de Yebenes JG (2004) The new mutation, E46K, of alpha-synuclein causes Parkinson and Lewy body dementia. Ann Neurol 55:164-173

73. Ziegler M, Oei SL (2001) A cellular survival switch: poly(ADP-ribosyl)ation stimulates DNA repair and silences transcription. Bioessays 23:543-548

74. Zhang Y, Dawson VL, Dawson TM (2000) Oxidative stress and genetics in the pathogenesis of Parkinson's disease. Neurobiol Dis $7: 240-250$

75. Zhang Y, James M, Middleton FA, Davis RL (2005) Transcriptional analysis of multiple brain regions in Parkinson's disease supports the involvement of specific protein processing, energy metabolism, and signaling pathways, and suggests novel disease mechanisms. Am $\mathbf{J}$ Med Genet B Neuropsychiatr Genet 137:5-16. Erratum in: Am J Med Genet B Neuropsychiatr Gene 139:122 